\title{
Participatory Education \\ Research for Capacity Building to enhance capabilities and quality of life of prisoners with hearing loss in New Zealand prisons: implications for social justice
}

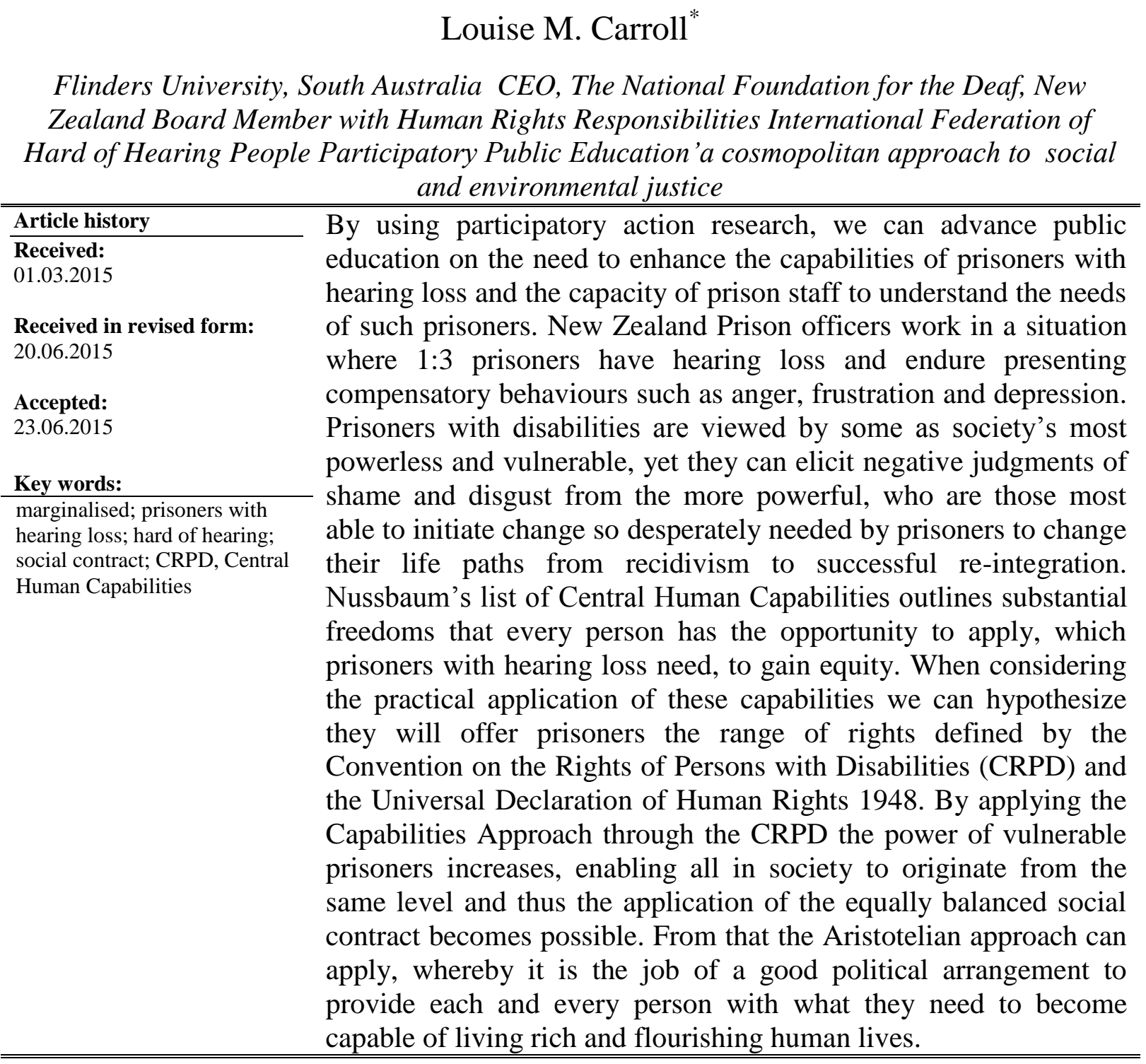

*Correspondence: louise.carroll@nfd.org.nz 


\section{Background}

Bowers (1982) offered a stark face to the distressing rate of hearing loss in New Zealand prisoners when reporting on hearing screening and hearing health histories of 100 European male and 100 Maori male prisoners. She suggested a number of policy recommendations to identify and support prisoners with hearing loss.

From this catalyst, research was done in 2014 to determine if access and equity is now extended to marginalized groups, with the needs of one marginalised group being considered: New Zealand prisoners with hearing loss.

One hundred male prisoners on remand at Mt Eden Corrections Facility (MECF), managed by Serco private prisons service in New Zealand participated in the research by volunteering through self-referral to be hearing screened and interviewed about their hearing health.

This article is in four sections; the first offers context by providing important background information; the second being pre-2014; the third section is 2014 research, which outlines the 2014 Serco Mt Eden Corrections Facility (MECF) research findings and in the fourth section are recommendations on how we can address the insidious issue of hearing loss in the New Zealand prison population.

\section{Context}

In the New Zealand prison population indications are that prisoners have a significantly increased rate of hearing loss in comparison to that of the general population. This raises the question of what happens when a brain is starved of adequate auditory input and stimulation. "It is widely assumed that the brain shapes our conscious experiences... [and conversely] [i]t is also known that the brain is in turn shaped by experience" (McIntyre-Mills, J.2010). Accordingly, "our thoughts as well as our perceptions are integrally dependent on our sense organs..." (Sen, A. 2009). Given this high degree of brain inter-dependence what happens to a person when a sensory faculty such as hearing fails to function as expected or indeed required and the hearing loss is unrecognised. Given that situation, compensatory communication support methods such as cochlear implants, hearing aids with or without remote microphone or FM capacity and or access to sign language are denied. Pediatric hearing loss is believed to be "more than a disability or a medical diagnosis, because... [p]rofound childhood deafness is ...a cultural phenomenon in which social, emotional, linguistic, and intellectual patterns and problems are inextricably bound together" (Sacks, O., 1990) and Dahl (2002) reports that developmental problems can result from early or congenital hearing loss. This underscores the essential need for and value of the New Zealand Newborn Hearing Screening Programme which was established and rolled out nationwide in 2010/2011.

Acquired hearing loss with adult onset, is reported to have "a pervasive negative effect on interactive and verbal communication and this factor greatly influences how a person is perceived, interpreted and defined by others". Dahl (1992) reported in a study done in British Columbia that Corrections staff were five times more likely to perceive inmate behavioural or personality problems as deviant (or abnormal) than to perceive them as indicative of a hearing problem and $55 \%$ of the inmates with partial hearing loss expressed concern about being misjudged or mislabelled.

In the New Zealand prison population prisoners will present with unrecognised or non- 
rehabilitated paediatric and adult on-set hearing loss and both groups will need active hearing loss identification and support to successfully communicate and integrate firstly into the New Zealand prison population; to participate in any rehabilitation programme while in prison and then at release back into their community.

The Royal National Institute for the Deaf/Action on Hearing Loss (AOHL) and the Deafness Forum of Australia (DFA) both state that some type of hearing loss occurs at the rate of 1:6 in the general population. There is a distinct lack of New Zealand epidemiological data in this regard. However we know that prisoners self-reported that 1:3 had some type of hearing loss (New Zealand Prisoner Health Research 2005).

If we use the RNID and DFA statistics of 1:6, we will have over 700,000 New Zealanders who have some type of hearing loss and prefer to use verbal communication. If we apply the data from New Zealand household or census data, which is a 1:10 conservative statistic, we still have over 450,000 New Zealanders with some type of hearing loss which makes the Hard of Hearing the largest sensory disability group nationally.

There are two distinct cultures in the hearing loss sector nationally and globally, one being those who view themselves culturally as members of the Deaf community and their preferred or primary form of communication is through New Zealand Sign Language (NZSL). Deaf Aotearoa New Zealand advises there are 11,000 people who use NZSL as a primary communication tool.

The other group, comprising by far the greatest number of New Zealanders with hearing loss are those whose hearing has deteriorated after they have developed verbal language skills and view themselves as Hard of Hearing, with their preferred or primary form of communication being verbal language

\section{Pre-2014}

We now consider the statistics of hearing loss globally. The World Health Organisation (WHO) states that "half of all cases of hearing loss are avoidable through primary prevention" (WHO: http://www.who.int/mediacentre/factsheets/fs300/en/)

Research has shown that there was no government response to recommendations from Bowers (1981) following her findings that $100 \%$ of Maori prisoner research subjects and $84 \%$ of European research subjects were found to have abnormal ears and/or hearing or a history of ear disease. Though, these results were viewed as contentious at the time, they clearly indicated there was a significant issue of previous or on-going ear disease and hearing loss in the New Zealand prison population.

Hearing loss was the most prevalent prisoner self-reported sensory disability (New Zealand Prisoners Health Survey 2005) . Hearing screening was not done, but the prison population self-reported that hearing loss occurred at the rate of 1:3 (over 33\%). These findings are slightly lower but reasonably in line with US research on prison populations where hearing loss occurrence is reported at $36 \%$ to $48 \%$.

Of the $1: 3, \mathbf{1 4 . 2} \%$ of prisoners reported experiencing difficulty hearing someone in a quiet room; $\mathbf{2 4 \%}$ experienced difficulty hearing someone on the other side of a room and $\mathbf{3 1 . 2 \%}$ experienced difficulty when having a group conversation. 
It is also reported in the 2005 Survey that prisoner access to medical care is haphazard, which supports the notion that referrals to hearing loss rehabilitation services will be haphazard too. Note that ear disease or the history of it was not surveyed, meaning that a comparison to Bowers' findings is not possible.

\section{Research}

Initially research discussions were held with the New Zealand Department of Corrections (Corrections) but these ceased when Corrections chose to use non standardised equipment to do prisoner hearing testing. The equipment Corrections was using, and anecdotally is reported to be continuing to use, is reputed as giving unreliable results.

However, shortly thereafter discussions commenced with Serco Private Prison service and in 2014, 100 self-selected male prisoners at Serco Mt Eden Corrections Facility (MECF) were given Pure Tone Audiometry hearing tests. These were carried out by three qualified hearing therapists employed by Life Unlimited Hearing Services who are funded by the New Zealand Ministry of Health to provide an adult aural rehabilitation service that includes screening audiometry. The therapists took their standardised equipment in to the prison one day a week for a period of three months.

The results of the hearing tests were categorised as No further action; Monitoring in 12 months; Referral to Audiologist; Referral to General Practitioner and Referral to ORL/ENT Specialist by General Practitioner. As can be seen in Table One, from the group of 100 prisoners who underwent the Pure Tone Audiometry hearing screening, 33 require Audiologist referral; 4 require General Practitioner referral and 15 require ENT/ORL specialist referral by their General Practitioner, giving a total of 52 who require further intervention.

Table 1. Prisoner Hearing Screening Results

\begin{tabular}{|l|l|}
\hline Result Category & Number of Prisoners \\
\hline No Further Action & $22 \%$ \\
\hline Monitoring in 12 months & $26 \%$ \\
\hline Referral to Audiologist & $33 \%$ \\
\hline Referral to General Practitioner & $4 \%$ \\
\hline $\begin{array}{l}\text { Referral to ORL/ENT Specialist by } \\
\text { General Practitioner }\end{array}$ & $15 \%$ \\
\hline Total & $100 \%$ \\
\hline
\end{tabular}

There are three population groups for our consideration in Table Two, one being the predominant ethnic groups found in the general population in 2013; the next being the proportion of the same ethnic groupings represented in the prison population in 2010 and the third being the proportions of the ethnic groups of the 52\% of prisoners found to have hearing loss in the Serco 2014 Hearing Loss Identification study. As can be seen in Table Two, in 2013, 10.9\% of the general population were Asian; 67\% were of European descent and 14\% of Maori; $7 \%$ were Pacific People and $1.1 \%$ were of unidentified ethnicity.

In 2010, 3.6\% of the prison population were Asian; $33.6 \%$ were of European descent and 50.9\% were Maori; $11.5 \%$ were Pacific People and $0.4 \%$ were of unidentified ethnicity. Thus, in comparison to the rates of Maori and Pacific People general population ethnicity statistics, Maori and Pacific People were significantly over-represented in prison populations.

In 2014 of the 100 prisoners who self-referred for hearing testing in the MECF Prisoner Hearing Loss Identification Project. 3\% were Asian; 39\% were of European descent and 
another 39\% were of Maori; $15 \%$ were Pacific People and Other 4\%.Of the 100 prisoners who self-referred for hearing testing, 52 prisoners were identified as requiring further intervention.

Of the 52 prisoners, $4 \%$ were Asian; $37 \%$ were European whilst $42 \%$ were Maori; $15 \%$ were Pacific People and Other comprised 2\%. Again, in this small group who self-referred for hearing testing both Maori and Pacific People were significantly over-represented.

Table Two. General Population v Prison Population Statistics - Prisoner Ethnicities

\begin{tabular}{|l|c|c|c|}
\hline Ethnicity & $\begin{array}{c}\text { \% of General } \\
\text { Population 2013 }\end{array}$ & $\begin{array}{c}\text { \% of Prison } \\
\text { Population 2010 }\end{array}$ & $\begin{array}{c}\text { Ethnicity \% of 52 } \\
\text { Prisoners requiring } \\
\text { further intervention }\end{array}$ \\
\hline Asian & $10.9 \%$ & $3.6 \%$ & $4 \%$ \\
\hline European & $67 \%$ & $33.6 \%$ & $37 \%$ \\
\hline Maori & $14 \%$ & $50.9 \%$ & $42 \%$ \\
\hline Pacific People & $7 \%$ & $11.5 \%$ & $15 \%$ \\
\hline Other & $1.1 \%$ & $0.4 \%$ & $2 \%$ \\
\hline Total & $100 \%$ & $100 \%$ & $100 \%$ \\
\hline
\end{tabular}

In conclusion to this section, it is important to emphasise these results are indicative of a serious issue that requires further, in-depth investigations, which are outlined in the Recommendations section below.

\section{Method}

During this research a number of participatory education research elements were applied. This included researcher lived experience of hearing loss and critical analysis of participatory research and disability theory; analysis on whether the policy recommendations from Bowers (1982) that would address hearing loss induced prisoner marginalisation to determine if they had been applied; dialogue and correspondence with the State Corrections service on the need to introduce hearing screening of prisoners; discourse and project design and delivery with the government contracted private prison service Serco and systems advocacy correspondence and meetings with the various Ministers of the Crown responsible for disability and Corrections portfolio's. Further participatory research elements were offered by the objective hearing testing done by the hearing therapists using standardized hearing testing equipment and by the self-selected group of 100 male prisoners recruited from a representative population. Pure tone audiometry and brief subjective hearing histories were recorded by non prison service hearing therapists using standardized equipment.

For the duration of this project there were crossing paths of objective and subjective participatory research which added in elements of complexity and pragmatism.

\section{Results}

It was evident that Bowers recommendations had not been implemented and that of the 100 prisoners who self-referred for testing, 52 required further assessment from audiological clinical services. Prisoners with hearing loss in New Zealand prisoners remain multiply marginalised as their hearing loss is not routinely identified at admission; they are geographically and socially isolated as a result of incarceration and they are democratically marginalised because a 2010 amendment to the Electoral Act bars prisoners sentenced and incarcerated since 2010 from voting in the General Elections. 


\section{Recommendations}

Though the pool of prisoners being tested was small at 100 and it was a self-selecting sample, the results imply that the number of prisoners with hearing loss in New Zealand prisons has not decreased since 2005 and that there is a significant and serious need to implement a range of recommendations across all Corrections and Serco facilities.

These include ensuring Serco and Corrections staff, who know how to communicate using New Zealand Sign Language are rostered on to work with Deaf prisoners who use New Zealand Sign Language to communicate. There is also a need to ensure that prisoners who have hearing loss and do not use New Zealand Sign Language to communicate are able to understand the judicial process by providing professional captioning services for Court and Parole Board hearings.Also, Serco, Corrections and the Ministry of Health Disability Support Services policy staff need to collaborate to develop a hearing loss rehabilitation fund that Corrections can use to purchase hearing testing and hearing rehabilitation services for prisoners. It is also very important to Identify prisoners who have hearing loss by placing the following check list, as used in the 2014 research, in the Prisoner Health Questionnaire.

\section{Difficult Hearing Situations}

$\begin{array}{lll}\text { - } & 1 \text { on } 1 \text { in quiet: } & \text { Y / N } \\ \text { - } & \text { In groups/background noise: } & \text { Y / N } \\ \text { - } & \text { Difficulty using the telephone: } & \text { Y / N } \\ \text { - } & \text { Hearing the telephone ring: } & \text { Y / N } \\ \text { - } & \text { Hearing radio and TV: } & \text { Y / N } \\ \text { - } & \text { At home/socially/at work: } & \text { Y / N }\end{array}$

If there is a response of more than one 'yes', this indicates the need for further hearing and auditory processing testing.

The next area of concern to be addressed is to ensure Serco and Corrections staff knows how a person who has hearing loss will present; behave and where they can go for assistance within the prison system. There is a real need to develop a DVD resource for Corrections front-line staff to see in their training forums, which will offer standardised information to all staff nationwide.

We also recommend that two future research projects are implemented. The first one is to set up a cohort of prisoners who have tested as requiring follow up in the Mount Eden Corrections Facility Prisoners with Hearing Loss Identification Project 2014 and track their levels of recidivism after hearing rehabilitation intervention. This may best be achieved by the establishment of a Hard of Hearing group or unit at MECF.

The second recommended research project is to carry out a hearing screening project of a cohort of 500 prisoners, using trained testers who are using standardised and approved hearing testing equipment. Discussions are now underway with MECF and with The University of Auckland in regards to the possibility of this research proceeding.

Of the 52 prisoners who were confirmed by testing as needing further audiological or clinical services, $4 \%$ were Asian; $37 \%$ were European whilst $42 \%$ were Maori; $15 \%$ were Pacific People and Other comprised $2 \%$. In this small group who self-referred for hearing screening both Maori and Pacific People were significantly over-represented. 
Though not conclusive due to the small number of prisoners being tested, these results clearly indicate that hearing loss needs to be considered and actively ruled out as an issue when a prisoner's rehabilitation and reintegration programme is being developed.

There is also a need to do hearing screening and record hearing health histories of a larger cohort of New Zealand prisoners - 500 prisoners - to gain conclusive data on the occurrence of hearing loss in the New Zealand prison population.

\section{Participatory Education Research Conclusions}

This was a unique participatory research collaboration of many parties including a lead researcher who has hearing loss; prisoners who did and did not have hearing loss; hearing health service screeners and management; State and private senior prison management; University Professors from Universities in New Zealand and Australia and Members of the New Zealand Parliament.

There was space and a need for all parties who participated in this project and for all of the different types of research methodology they brought to the table which fitted nicely under the guise of participatory research.

It was a successful venture in New Zealand as positive change is happening for prisoners with hearing loss. The project is now being replicated in Australia where a similar project is being established with 100 woman prisoners.

\section{References}

Dahl, M., 2002, 1457 Morrison St, Port Coquitlam, British Columbia V3C2N6.

McIntyre-Mills,J.. 2010. 'Wellbeing, Mindfulness and the Global_Commons', Journal of Consciousness Studies, Volume 17, Numbers 7-8, 2010, Imprint Academic

New Zealand Prisoner Health Research (2005) Public Health Intelligence Occasional Bulletin No 37

Sen, A. 2009. The Idea of Justice. Position, Relevance and Illusion. The Belnap Press of Harvard University Press, Cambridge, Massachusetts.

Sacks, O. 1990 Seeing Voices. Vintage Book, a division of Random House Inc. New York. Who: http://www.who.int/mediacentre/factsheets/fs300/en 